\title{
SYMPOSIUM
}

\section{Sociodemographic context of the AIDS epidemic in a rural area in Tanzania with a focus on people's mobility and marriage}

\author{
J T Boerma, M Urassa, S Nnko, J Ng'weshemi, R Isingo, B Zaba, G Mwaluko
}

Sex Transm Infect 2002;78(Suppl I):i97-i105

This analysis focuses on how sociocultural and economic characteristics of a poor semi-urban and rural population (Kisesa ward) in north west Tanzania may directly and indirectly affect the epidemiology of HIV and other sexually transmitted infections (STI). Poverty and sociocultural changes may contribute to the observed high levels of marital instability and high levels of short and long term migration in Kisesa, especially among younger adults. Marriage and migration patterns are important underlying factors affecting the spread of HIV. The most cost-effective intervention strategy may be to focus on the trading centre in which mobility is higher, bars were more common, and HIV prevalence and incidence were considerably higher than in the nearby rural villages. If resources suffice, additional work can be undertaken in the rural villages, although it is not clear to what extent the rural epidemic would be self sustaining if the interventions in the trading centre were effective.

See end of article for authors' affiliations

Correspondence to Dr J Ties Boerma Department of Epidemiology, School of Public Health, and Carolina Population Center, University of North Carolina, Chapel Hill, NC 27516-3997, USA ties_boerma@unc.edu

Accepted 30 November 2001
W ith an estimated $71 \%$ of the estimated 34.3 million adults and children living with HIV, the AIDS epidemic in subSaharan Africa is much more severe than in any other continent in the world. ${ }^{1}$ A range of sociocultural, political, and economic factors is thought to favour HIV transmission in many African societies to a much greater extent than elsewhere in the world. ${ }^{2}{ }^{3}$ In addition, within subSaharan Africa large differentials in HIV prevalence have been observed between countries, between regions of the same country, between urban and rural areas in the same region, and within rural areas. ${ }^{4-6}$ Many factors, ranging from socioeconomic and demographic features to sexual behaviour patterns, male circumcision practices, and the prevalence of incurable sexually transmitted infections (STI) have been held responsible for the uneven spread of HIV within the continent. ${ }^{7}$

Studies in western societies have shown the key role of core groups in the epidemiology of sexually transmitted infections. ${ }^{8}$ Recent studies in Asia have indicated the importance of bridge populations, of which members have sex with both members of core groups and of the general population.. ${ }^{10}$ There are also studies, mainly among sex workers, in sub-Saharan Africa that have pointed to the importance of core groups in STI epidemics. ${ }^{11-13}$ On the other hand, the HIV prevalence in several sub-Saharan African countries has reached levels that suggest widespread occurrence of risk behaviours in the general adult population, and this is corroborated by findings from sexual behaviour surveys. ${ }^{14}$ With the exception of some cities, commercial sex is less prominent than in, for example, Thailand, and core groups appear to be much larger and less clearly identifiable.

Wasserheit and Aral $^{15}$ have proposed a dynamic typology of STI epidemics which emphasises the distinction between spread networks (characterised by higher rates of concurrent partnerships, by large numbers of sexual linkages throughout the subpopulation, and by some sexual contact with other subpopulations) and maintenance networks (located in subpopulations with relatively lower rates of sexual mixing). The STI epidemic is divided into four phases, starting with an early growth phase, followed by hyperendemic, decline, and endemic phases. Intervention programmes should adapt to the role of the networks in the different phases. In early phases prevention efforts should include efforts raise general public awareness of the "new" STI and improved counselling, detection, and treatment services, with concerted and additional efforts for spread networks. In the subsequent stages prevention strategies should focus more on outreach and community level behavioural interventions in hard to reach populations and less on general population interventions.

Hitherto, research and interventions strategies in the AIDS epidemic in sub-Saharan Africa have primarily focused on raising knowledge and awareness in the general population, on condom promotion to the general public, and on the control of sexually transmitted diseases in the general population or in specific high risk groups. The targeted high risk groups - as representatives of the spread network-are most commonly female commercial sex workers, truck drivers, and sometimes long distance migrant labourers. ${ }^{216}$ Currently, the case is made for more emphasis on interventions focused on high risk subpopulations, in part motivated by epidemiological considerations but largely driven by resource limitations in proportion to the huge epidemic. ${ }^{17}$ In order to effectively plan, implement, and evaluate such interventions there is a need for a better description of the composition and dynamics of spread networks.

In this paper we describe the context of the AIDS epidemic in a small rural area in Tanzania, 


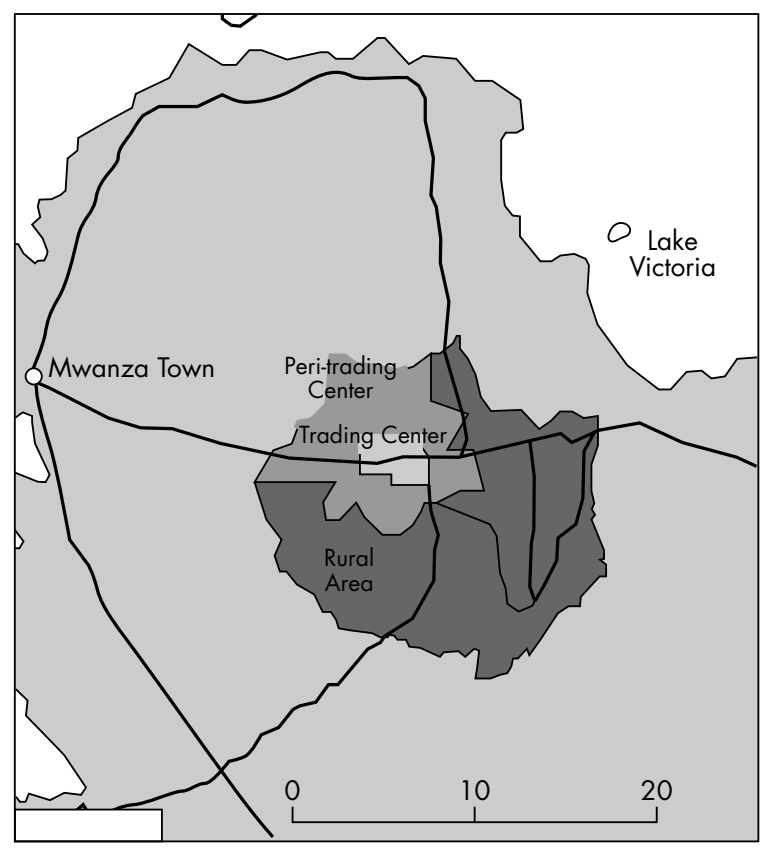

where a population of about 20000 people has been followed since 1994. This analysis includes the period 1994-98 and focuses on population characteristics rather than on individual risk factors. Special attention is given to population mobility and marriage patterns and how these relate to sexual behaviour and HIV infection at the community level. It is shown that mobility and marriage are critical contextual factors in this population, and sexual mixing is dynamic and diffuse. An area based strategy, focusing on places with high new partner acquisition rates, ${ }^{18}$ appears an appropriate alternative to conventional sex worker focused approaches, and can help focus interventions in the hyperendemic and subsequent phases of the epidemic.

\section{DATA SOURCES}

Kisesa ward is located in Mwanza Region in northwest Tanzania, about $20 \mathrm{~km}$ east of the regional capital Mwanza, along the main road to Kenya (fig 1). It includes six villages with a trading centre along the main road, which have been grouped into trading centre, peritrading centre, and agricultural rural villages for the purpose of this study. ${ }^{6}$

A demographic surveillance system was established in 1994 and collects basic demographic information through household visits every five months, and by late 199810 rounds had been completed. ${ }^{6}{ }^{19}$ All households are visited each round, and information is collected on residence and survival status of all household members, on pregnancy of women of reproductive ages, and on new arrivals (migrants, newborns). A new person was only listed as a household member if the household respondent had indicated that this person was intending to stay in the household. People who had left the household by the next round were not considered household members. For each resident it was asked whether or not that person had slept in the household the night preceding the visit.

Epidemiological and behavioural surveys of all adults aged 15 to 44 years were carried out during 1994-95 and again two years later. In all, 5820 and 6413 respondents participated in the first and second survey, respectively (response rates $78 \%$ and $80 \%$ ). The surveys included a structured interview on background characteristics, AIDS knowledge and attitude, sexual behaviour, STI treatment, and so on, and collection of a blood sample for HIV and syphilis testing in the first survey and HIV only in the second survey. ${ }^{6}$
Figure 1 Map of Kisesa.

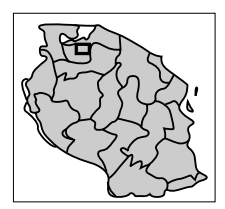

The second survey included a sexual mixing module, which obtained information on all marital partnerships and on the last five non-marital sexual partnerships in the last year. This module included information on the age, marital status, and place of residence of the sexual partner. The 3684 respondents of the sexual network module (1651 men and 2033 women) reported 2439 non-marital partnerships in the last year. Reports were obtained from a total of 1130 male and 803 female spouses, and 554 male and 1990 female non-marital partners with whom respondents had sexual relations in the last year. ${ }^{20}$

A travellers survey was conducted in 1997. The field workers counted vehicles and interviewed travellers during a single week on all primary and secondary roads in the area. Qualitative methods were used to collect data on mobility, characteristics of bars, and commercial sex. Local informants listed all bars, including traditional brew selling points called pombe shops. Field workers and local informants listed all bar and pombe shop workers and women who frequent such places and are willing to have sex for a small payment or gift. Data on health service utilisation by STI patients were derived from routine records of all health facilities in the study area. All traditional healers in the study area were also interviewed about STI treatment and other conditions. ${ }^{21}$

\section{STUDY SETTING}

The total population of Kisesa ward was 19458 in 1994 and grew $2.5 \%$ a year to 21774 by the 10 th demographic round in late 1998. The latter included 12073 people living in the rural villages, 4085 in the peri-trading centre area, and 5616 in the trading centre. The population grew more rapidly in the peritrading centre area and trading centre (3.7 and 3.4\% a year, respectively) than in the rural villages (1.7\%). Nearly half of the population is under 15 years $(46 \%)$ and large cohorts of young people will be moving into the reproductive age span in the coming years. For example, while $10.2 \%$ of the population are aged 15 to $19,13.2 \%$ are aged 10 to 14 years.

Data from the survey in 1994-95 are used to describe a few basic features of the Kisesa adult population aged 15 to 44 years. The predominant ethnic group were Sukuma (95\% of 5751 respondents). Christianity was the most common religion $(74 \%)$, followed by traditional religion $(23 \%)$ and Islam (3\%). Thirteen per cent of men and $29 \%$ of women were 
illiterate, and only $5 \%$ of men and $2 \%$ of women had secondary school education or higher. Farming was the main source of income, while petty trade of agricultural products (milk, tomatoes, maize, rice, fish, etc) was common. No data were collected on household income in monetary terms. In 1994, $38 \%$ of households owned a radio, 39\% had at least one bicycle, and $2 \%$ had a motorised vehicle. Annual income in this rural population with recurrent droughts and shortage of offfarm employment is likely to be of the same order of magnitude or somewhat lower than the Tanzanian gross domestic product (GDP) per head, which was estimated to be about US\$120 in $1995 .^{22}$

Traditionally, the Sukuma do not circumcise, although recent data indicate a popularisation of the practice of male circumcision, as about $21 \%$ of Sukuma men aged 15 to 44 years in Kisesa ward reported themselves circumcised. ${ }^{21}$ Postpartum sexual abstinence is fairly short, as about two thirds of women had resumed sexual intercourse within six months after giving birth.

\section{PREVENTION EFFORTS}

The HIV/STI prevention activities of the Tanzania National AIDS Control Programme (NACP) have primarily focused on condom promotion and distribution (initially through free condoms distributed to health facilities, and later also through social marketing), raising awareness and knowledge of the AIDS epidemic, postponement of first sex in adolescence, and health education to the general public to reduce multiple partnerships. The Tanzania-Netherlands project to support AIDS control in Mwanza region (TANESA) collaborates with its local partners (Regional Medical Office, National Institute for Medical Research, and Bugando Medical Centre) to develop new interventions and support the implementation of national programmes. In the context of the Kisesa community study, the aim was not to develop and evaluate a large and well defined intervention but to focus only on supporting the regular AIDS activities of the district through the district authorities, and to provide other non-AIDS-related community support to compensate for the study participation. The district budget for AIDS control activities was very small, barely sufficient to pay one Ministry of Health staff member with a motorbike to supply condoms and provide AIDS education at government health facilities in a district of more than 300000 people, including an estimated 10000 infected adults. Non-government organisations and the private sector have limited coverage in the district and Kisesa ward. The main HIV/STI control activity was the introduction of the syndromic approach for the treatment of STIs, supported by AMREF, a non-government organisation, and the European Commission, following the successful intervention trial in Mwanza Region. ${ }^{23}$

Until 1996 the main interventions were increased availability of condoms, mainly through the health facilities, and health education of the general public. Towards the end of 1996 several community interventions were introduced in Kisesa to promote safer sexual behaviour. These interventions covered Kisesa trading centre and one rural village and included community mapping of high risk places, establishment of village AIDS committees, community campaigns against AIDS, formulation of village bylaws to reduce high risk sexual behaviour, and school based AIDS education. Towards the end of the study period social marketing condoms were introduced in shops. Voluntary HIV counselling and testing was offered during the 1996-97 survey, but few participants made use of this service (less than $1 \%$ of the survey participants). Virtually all respondents had heard of AIDS (99.5\% in 1996/97), and knew HIV could be transmitted by sex (97\%). However, only $68 \%$ said a healthy person could have HIV.
There were three government dispensaries (a fourth was opened in 1996), one private health facility, and 38 traditional healers in Kisesa ward (in 1994). As part of the regional effort to strengthen STI services, syndromic treatment, including regular supervision and improved drug supplies for STI treatment, became available in one government dispensary in late 1994, and in two other dispensaries in mid-1996. From the time of the introduction of the syndromic approach, data on the numbers of STI clients have been available.

\section{MARRIAGE, MOBILITY, AND THE RISK OF INFECTION}

As HIV and other STIs affect various subpopulations, and their extent and spread are directly or indirectly affected by a wide range of underlying factors that may be interrelated. ${ }^{15}$ In demographic research, proximate determinant models have often been used to study the determinants of fertility ${ }^{24}$ and of child mortality. ${ }^{25}$ The key feature of these models is the identification of a set of proximate determinants through which social, economic, and cultural factors affect fertility or child mortality, forming the hinge between the social and biological systems. These proximate determinants are behavioural and biological in nature: they can be changed by social change or interventions, and if they change there is a direct biological effect on fertility or on child health and mortality. In case of HIV/AIDS the proximate determinants can be defined as the components of the basic reproduction rate of infection, which is determined by the rate of sex partner change, the risk of transmission per sexual act, and the duration of infectiousness.$^{26}$ Underlying demographic, socioeconomic, and sociocultural factors must operate through these proximate determinants to affect the risk of HIV infection. In the African context, marriage patterns and population mobility are two very important underlying factors that affect the proximate determinants, especially the rate of sexual interaction between infected and susceptible people.

\section{Marriage}

It has been emphasised that marriage in the African context should be viewed as a process and that it may not be clear when a woman is married or not. ${ }^{27}$ Important features of contemporary marriage systems in sub-Saharan Africa are declining levels of polygyny, increasing levels of noncustomary marriage, and higher rates of marital dissolution. ${ }^{327}{ }^{28}$ Such changes are more common in urban areas. Typically there are substantial age differences between marital partners in many populations, and age at first marriage among women is often well below 20 years. In a context of permissiveness toward premarital sexual activity ${ }^{3}$ this is likely to influence premarital partner selection and enhance age mixing. If premarital sexual behaviour involves partnerships between young women and older men, this may introduce premarital infections at an early age. Indeed high rates of HIV infection among teenage girls have been observed $^{29}$ but not among teenage boys, and there is considerable variation between societies. High rates of divorce or separation and remarriage may also affect partnership formation patterns and facilitate higher levels of partner turnover and concurrent partnerships in the population. High levels of extramarital partnerships indicate high levels of concurrent partnerships as well.

Table 1 summarises selected indicators of current and past marital behaviour among respondents in the 1996-97 survey. The median age at first marriage for women was 19 years and for men 23 years, and 5\% of men and $15 \%$ of women were in a polygynous union. Virtually all men and women in a monogamous union were living in the same household. Among women in a polygynous union, $92.5 \%$ were cohabiting with their husbands. 
Table 1 Indicators of marriage patterns, Kisesa, 1996-97

\begin{tabular}{|c|c|c|c|c|}
\hline & Men & & Womer & \\
\hline \multirow[t]{2}{*}{ Median age at first marriage (years) } & \multicolumn{2}{|l|}{23.2} & \multicolumn{2}{|l|}{19.0} \\
\hline & $\mathrm{n}$ & Per cent & $\mathrm{n}$ & Per cent \\
\hline \multicolumn{5}{|l|}{ Current marital status } \\
\hline Single & 2916 & 48.5 & 3497 & 18.0 \\
\hline Married, monogamous & 2916 & 41.5 & 3497 & 55.1 \\
\hline Married, polygamous & 2916 & 4.6 & 3497 & 15.4 \\
\hline Widowed & 2916 & 0.3 & 3497 & 1.9 \\
\hline Divorced/separated & 2916 & 5.2 & 3497 & 9.7 \\
\hline \multicolumn{5}{|l|}{ Co-residence marital partners } \\
\hline Married monogamously, not co-residing & 1211 & 0.8 & 1925 & 1.6 \\
\hline Married polygamously, not co-residing & 133 & 0.8 & 537 & 7.5 \\
\hline \multicolumn{5}{|l|}{ Marital history } \\
\hline Among ever married, at least one broken marriage & 1498 & 44.8 & 2855 & 33.9 \\
\hline Among ever married, at least two broken marriages & 1498 & 11.1 & 2855 & 5.6 \\
\hline \multicolumn{5}{|l|}{ Type of marriage } \\
\hline Informal marriage & 805 & 25.3 & 1439 & 43.0 \\
\hline Bride price not paid in full or not at all & 805 & 41.6 & 1437 & 45.1 \\
\hline
\end{tabular}

Divorce and separation were common. Five per cent of men and $10 \%$ of women were divorced or separated at the time of interview. Almost half of ever married men and one third of ever married women had divorced at least once. As current status data indicate much lower divorce rates, remarriage is likely to be very common and occurs fairly soon after divorce. Men and women who were divorced at the time of the second survey were asked for the reason of the break up of their most recent marriage. Among 118 male respondents the most common reason was unfaithfulness of their partner $(55 \%$ of men said so), followed at a distance by lack of love (16\%), infertility $(6 \%)$, alcoholism of the wife $(6 \%)$, and no payment of bride price (5\%). Among 314 female respondents, alcoholism of the husband (38\%), lack of love (31\%), unfaithfulness $(27 \%)$, and violence $(24 \%)$ were the most common reasons for divorce, followed by non-payment of bride price $(7 \%)$ and infertility $(3 \%)$.

The sexual mixing module collected additional information about current marital partnerships. An informal marital relationship ("mapatano", defined as a cohabitation which was not preceded by a traditional, government, or church wedding) was reported by $25 \%$ of men and $43 \%$ of women. In $40 \%$ of marital relationships it was reported that the bride price had not been paid in full, and mostly nothing had been paid at all. This primarily involved informal cohabiting relationships, but also pertain to some traditional or church marriages.

\section{Mobility}

Population mobility is high in much of Africa and may also enhance the rate of partner change and the introduction of new infections into less mobile populations. ${ }^{30}{ }^{31}$ This may involve mobility during crises and emergency situations, but much larger populations are involved in permanent or circular migration to urban areas ${ }^{31} 32$ or in short term movements within or between urban and rural areas. Labour migration is a prime reason for permanent migration and for seasonal mobility leading to prolonged separation of partners and families. Marriage (or less formal cohabitation arrangements) and divorce or separation are also important reasons for migration. Studies in Senegal ${ }^{33}$ and Uganda ${ }^{34}$ have shown that migration is an independent individual risk factor for the acquisition of HIV, irrespective of origin or destination. Other studies have suggested that raised levels of HIV prevalence can be observed in fairly small settlements, such as trading centres, along main roads, where mobility is common. ${ }^{5635}$
In the demographic surveillance system in Kisesa, a person aged 15 and over was considered a member of a household if he or she had stayed at least two rounds in a household and the head of the household indicated that this member was intending to stay. Migration rates were assessed by looking at the presence in the last demographic round (round 10, after four years) among persons aged 15 to 59 who had been present in the first two demographic rounds. Overall, $10 \%$ of men and $12 \%$ of women moved each year during the study period (table 2). In the trading centre migration rates were highest. Figure 2 examines annual migration rates by age group. Female migration rates are higher because of very high migration rates among women under 25 years. Male and female migration rates are identical at ages 25 and over. In the trading centre male migration rates peak at ages 25 to 29 (18\% per year).

A large proportion of migration took place within the same village: four of 10 men and women moved within the same village. The reasons for moving were collected but data were incomplete. Among those female migrants aged 15 to 49 for whom a clear reason was given, marriage and divorce/ separation were the most important reasons for permanently leaving a household $-25 \%$ did so because of marriage and $12 \%$ because of divorce/separation. This marriage/divorce ratio suggests high marital dissolution rates. As women often move into the new husband's household, marriage or divorce was less often a reason for moving among men (11\%).

Short term mobility was assessed using data from the demographic surveillance system and the travellers' survey. For each demographic round, data were collected on whether or not each resident had slept in the household the night

Table 2 Annual migration by place of residence among men and women 15-59 years, Kisesa 1994-1998

\begin{tabular}{llllll}
\hline & \multicolumn{2}{l}{ Men } & & \multicolumn{2}{l}{ Women } \\
\cline { 2 - 3 } \cline { 5 - 6 } & $\mathrm{n}$ & $\%$ moved & & $\mathrm{n}$ & $\%$ moved \\
\hline Rural villages & 2415 & 9.0 & & 2420 & 11.2 \\
Peri-trading centre & 751 & 10.2 & & 751 & 12.0 \\
Trading centre & 1025 & 13.7 & & 1135 & 13.9 \\
All & 4191 & 10.3 & & 4306 & 12.1 \\
\hline
\end{tabular}




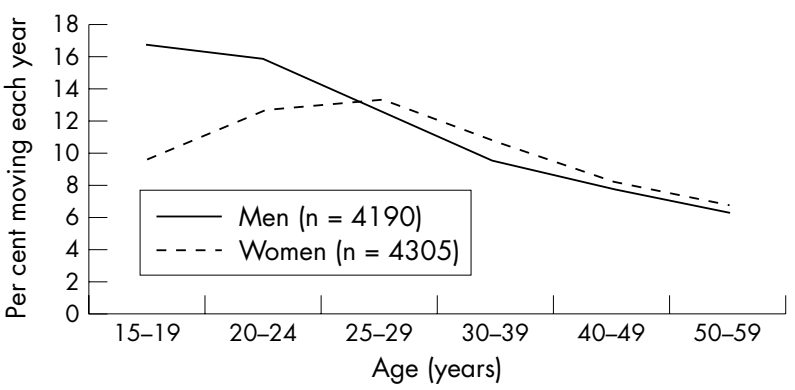

Figure 2 Annual migration among men and women 15 to 59 years by age in Kisesa, 1994-98.

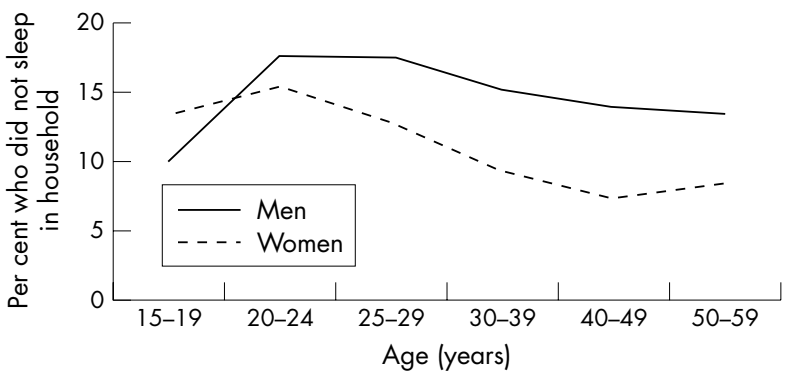

Figure 3 Daily mobility: not sleeping in household on night before visit in Kisesa, by age.

before: $14 \%$ of men aged 15 to 59 and $11 \%$ of women aged 15-59 had not slept in the household the night before. Men were more commonly absent at all ages, and increasingly at older ages, except at 15 to 19 years (fig 3 ).

Field workers counted and interviewed all travellers on seven main "checkpoints" within the study area during one day. Four checkpoints were along the main road that cuts through the study area. Bus travellers were only counted if the bus stopped and the passengers got off the bus in Kisesa. Overall, 4798 travellers were interviewed and $76 \%$ of those were male. A few were under 15 years old (7\%), 41\% were aged 15 to 29 , and $52 \%$ were 30 or older. More than a third travelled alone $(38 \%), 55 \%$ were in groups of two or three persons, and $7 \%$ were among four or more persons. The predominant mode of transportation was bicycle $(65 \%)$, followed by walking $(22 \%)$, car $(8 \%)$, and bus $(6 \%)$.

The checkpoint at the trading centre had the largest volume of all checkpoints, and $27 \%$ of 1306 travellers were on the way to Mwanza town. At the rural checkpoints very few travellers were heading for Mwanza town, but a large proportion were on their way to the trading centre. About two thirds of the travellers said they intended to return the same day, with little variation by destination. Overall, a remarkably high proportion of travellers said they did not know when they would return $(29 \%)$. This may be because they indeed did not know, or because they did not want the interviewer to know.

The main purpose of the journey differed between travellers to town or trading centre and travellers to the rural villages. Buying or selling, of mostly agricultural products, was the main reason among $60 \%$ and $68 \%$ of those going to town or the trading centre, respectively, compared with 37\% among travellers between the rural villages. Among the latter, visiting relatives was also a common reason for travel $(34 \%)$, which was mentioned by $13 \%$ and $16 \%$ of those with a town or trading centre as a destination, respectively. Ceremonies (marriage, burial, and so on) were mentioned as the main reason for travel to the rural villages by $11 \%$ of respondents.

\section{SEXUAL BEHAVIOUR}

\section{Abstinence, multiple partners, and condoms}

Selected indicators of sexual behaviour based on the 1996-97 survey are shown in table 3 . The age at first sex was computed using a survival analysis based on current status (ever had sex) and recall data. Based on respondents under the age of 25 , the median age at first sex was about 16 years for women in both surveys and 17 years for men. Most never married men and women were involved in sexual relationships.

Multiple partnerships were frequently reported. For instance, during the second survey $9 \%$ of men reported more than two partners in the last month and $29 \%$ more than two partners in the last year. Only $0.5 \%$ of men reported 12 or more partners in the last year. Almost half the married men reported an extramarital partner in the last year. Less than $2 \%$ of women reported two more partners in the last month, or three or more in the last year. There was little evidence of change in the reporting of the frequency of multiple partnerships by men between the two surveys (data not shown).

Condom use was low. In 1996-97, 85\% of men and $69 \%$ of women said they had ever heard of condoms, and $18 \%$ of men and $4 \%$ of women had ever used a condom. Condom use within marriage was negligible, and with regular noncohabiting partners or with casual partners it was below $10 \%$. For example, $8 \%$ of men reported that they always used a condom during casual sex, and an additional 17\% sometimes used a condom. Among women the corresponding figures were $7 \%$ and $6 \%$ for always and sometimes, respectively.

\begin{tabular}{|c|c|c|c|c|}
\hline & Men & & Women & \\
\hline \multirow[t]{2}{*}{ Median age at first sex among $15-24$ year olds (years) } & 17.3 & & 15.8 & \\
\hline & $\mathrm{n}$ & Per cent & $\mathrm{n}$ & Per cent \\
\hline \multicolumn{5}{|l|}{ Adolescence } \\
\hline Premarital sex among ever married, $15-24$ year olds & 1220 & 73.8 & 584 & 65.4 \\
\hline \multicolumn{5}{|l|}{ Multiple partners } \\
\hline Had non-marital non-cohabiting partner in last year & 2916 & 59.0 & 3497 & 24.9 \\
\hline Two or more partners in last month & 2916 & 8.9 & 3497 & 1.7 \\
\hline Three or more partners in last year & 2916 & 28.5 & 3497 & 1.9 \\
\hline Extramarital partner in last year & 1344 & 44.7 & 2460 & 4.3 \\
\hline \multicolumn{5}{|l|}{ Condoms } \\
\hline Ever used & 2916 & 18.2 & 3497 & 3.7 \\
\hline Uses sometimes with marital partner & 1338 & 7.8 & 2460 & 0.9 \\
\hline Uses sometimes with regular partner & 784 & 18.4 & 602 & 4.2 \\
\hline Uses always with regular partners & 602 & 2.3 & 602 & 1.5 \\
\hline Used sometimes with casual partners & 1430 & 17.4 & 261 & 6.1 \\
\hline Uses always with casual partners & 1430 & 8.0 & 261 & 6.5 \\
\hline
\end{tabular}




\section{Sexual mixing patterns}

Additional data on sexual mixing and characteristics of partnerships were collected in the sexual mixing module which was administered during the 1996-97 survey. The main results include ${ }^{36}$ :

- Forty two per cent of partnerships reported by men and 13\% of those reported by women lasted less than one month.

- Men were overall about seven years older than their wives, and about five to six years older than their non-marital sexual partners. Girls under 20 years reported sexual partners who were on average 5.3 years older than themselves; $9 \%$ had a non-marital partner aged 30 and over, and $20 \%$ had a spouse aged 30 and older. Older men (30 and over) tended to have non-marital partners who were younger than their wives.

- There was limited mixing between the rural villages and the trading centre, or between the ward as a whole and the nearby regional capital. Almost three quarters of the non-marital partnerships in the rural areas were within the same area. Nearly $90 \%$ of the partnerships that were reported by men living in the rural areas were with women from the same or other rural villages; $83 \%$ of partnerships reported by rural women were with partners from within the rural area.

- Women report a slightly higher proportion (13\%) of non-marital partners from outside the study area (Mwanza town or far away) than men (9\%). Higher proportions of women $(7 \%)$ who live in the rural villages than men $(2 \%)$ reported having lovers in the trading centre at Kisesa, but women were less likely than men to report partners from other villages. Two per cent of men and $8 \%$ of women respondents reported sexual contacts with people from Mwanza town.

- Nearly all extramarital partnerships reported by men involved unmarried women, single or divorced (96\%).

- Using the level of education as an indicator of social class, mixing between men from higher social classes with women from lower social classes was fairly common, but not the other way around.

- In an average month during the six month period preceding the interview, $16 \%$ of unmarried men, $21 \%$ of married men, and $2 \%$ of women (married or not) were involved in overlapping partnerships. The interval between ending one partnership and beginning a new one was short in most instances. Most partnership endings involved single men. Among 937 non-marital partnership endings reported by single men, $27 \%$ had another non-marital partnership ongoing, $9 \%$ started a new partnership in the same month in which the previous partnership ended, and 28\% started a new partnership with at least a gap of one month.

\section{Commercial sex}

The male field workers listed all women available for sex in exchange for money, using key informants. In total, 365 women were listed. Four groups were distinguished by the informants and field workers: bar workers $(42 \%$ of all women), women who visit bars and solicit sex (30\%), women who live alone and can provide sex in their house ("guesti bubu") (20\%), and women who sell sex only if they badly need money $(8 \%)$. None of these women were labelled as commercial sex workers. As was shown in a study of female bar workers elsewhere in the district-and supported by intervention work with women working in bars in nearby Mwanza townthere is no clear distinction between commercial and non-commercial sex. Some have a regular partner and an occasional casual partner, while others have larger numbers of casual contacts. ${ }^{37}$ Mobility among bar workers was high. No detailed data were collected on the price of sex, but qualitative
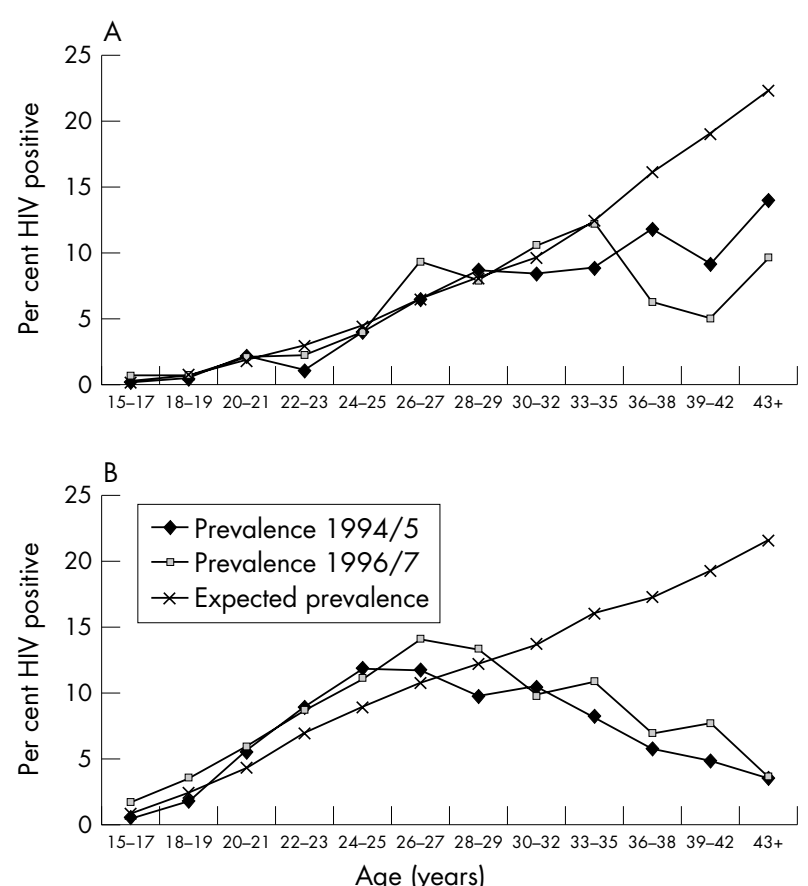

Figure 4 (A) Observed and "expected" HIV prevalence among men, Kisesa 1994-97. (B) Observed and "expected" HIV prevalence among women, Kisesa 1994-97. The expected HIV prevalence is based on the incidence rates in the period between the two surveys.

data suggest that the price of sexual intercourse with a "sex worker" was below US\$1 in most instances (the official minimum wage for a day's work was about US\$1.50). For Kisesa, the number of women listed as available for sex for money was around 1 per 14 men aged 15 and over.

\section{HIV/STI EPIDEMIOLOGY \\ HIV by age and sex}

HIV prevalence among men and women aged 15 to 44 was $5.8 \%$ in $1994 / 95$ and $6.6 \%$ in 1996/96, while HIV incidence in the intersurvey period was 0.7 and 0.8 per 100 person years among men and women respectively. ${ }^{6}$ Figure 4 presents the observed HIV prevalence in both surveys and the "expected HIV prevalence," derived from HIV incidence rates, by age for men and women separately (in two year and, at older ages, three year age groups, with the sample size exceeding 125 in all age groups). The "expected HIV prevalence" represents hypothetical prevalence if a 15 year old were exposed to the current incidence rates until age $\mathrm{x}$ and was calculated from the HIV incidence rates.*

For both sexes the shapes of prevalence curves are similar, with a small increase in the 1996-97 survey. The expected HIV prevalence initially lies close to the prevalence curves. Observed HIV prevalence and expected prevalence curves diverge from age 26 to 27 for women and age 30 to 32 for men,

* The HIV incidence rate can be treated analogously to the central death rate, ${ }_{n} M_{x}$ in a life table, as it is a ratio of events to persons years at risk. In life table terms, the age pattern of stable prevalence associated with a given regime of incidence rates is given by the complement of the proportionate person years function $\left(\left(1-{ }_{n} L_{x}\right) / n\right)$. Obtaining the person years $L_{x}$ function from the central rate, $M_{x}$, is a standard straightforward calculation, provided we can make some simplifying assumptions about the linearity of change with age in the proportion of susceptibles, $I_{x}$, in the population - within the narrow two and three year age intervals considered here, such an assumption is justified. 
which is likely to be associated both with increased HIV associated mortality and possibly a discrepancy between current and past incidence among older cohorts. For women the curves show an almost linear increase during the first 10-15 years after the initiation of sexual intercourse (15-17 years). The increase among women has a steeper slope than among men. HIV prevalence among women exceeds $5 \%$ at about 20 and $10 \%$ at 25 years of age. Male HIV prevalence reaches these levels at an age five to six years older.

\section{HIV by residence and mobility}

The surveys revealed striking differences in HIV prevalence and incidence within the small geographical area. HIV prevalence in the trading centre was twice that in the area surrounding the trading centre (within $2 \mathrm{~km}$ ), and three to four times higher than in the rural villages (within $8 \mathrm{~km}$ of the trading centre). ${ }^{6}$ Analysis of individual risk factors of HIV infection showed that the large impact of the community factors remained after controlling for multiple individual demographic, socioeconomic, biological, and behavioural variables. ${ }^{38}$ The main community characteristics that affected the risk of HIV included level of economic and social activity, numbers of female bar workers in the community, mobility of the population, and proximity to town. There were also some differences in sexual behaviour between communities, but these were fairly modest and did not explain the effect of community on the risk of HIV.

Other studies have shown an association between HIV prevalence and individual mobility. ${ }^{34}$ Also, in Kisesa those who moved into the ward had a higher prevalence than those who had lived in the ward all their lives, although the differences were fairly small and became smaller when other variables were controlled for. ${ }^{38}$ The lower participation rates in a survey of more mobile individuals is, however, an important bias for the individual level analysis. The main reason for nonparticipation in the survey was travel, short term or long term. ${ }^{6}$ Current marital status (being divorced or separated) and a history of divorce were strongly associated with the risk of HIV, in analyses of both prevalence and incidence.

\section{Other sexually transmitted infections}

Serological data on other STIs were only available from the first survey in 1994-95, when whole blood was collected and Treponema pallidum haemagglutination assay (TPHA) and Venereal Diseases Research Laboratories (VDRL) tests were done in the laboratory. Overall, $15.5 \%$ of 2455 men had a positive TPHA test, including $11.3 \%$ who also had a positive VDRL test, which is taken as evidence of recent or current syphilis. Among 2641 women the corresponding figures were 20.5\% with a positive TPHA test and $15.8 \%$ with a positive TPHA and VDRL test. Positive reactions were least common among men and women aged 15 to 19 , and there was little variation from that age onward.

Self reported data were collected for genital discharge and genital ulcer in the 12 months preceding the survey. In 199697, $10.2 \%$ of men and $6.3 \%$ of women reported a genital discharge in the last year, while $10.8 \%$ of men and $4.6 \%$ of women reported a genital ulcer in the last year. Among men and women with a self reported genital discharge or ulcer, $46.1 \%$ and $38.9 \%$, respectively, had visited a health facility for treatment. Traditional healers were the second most popular source of treatment (used by $23.1 \%$ and $22.8 \%$ of men and women, respectively). During the interviews with traditional healers, however, only a few said they treated large numbers of patients, which may indicate that the traditional healers play a relatively limited role in the treatment of STIs in this area. ${ }^{21}$

The three dispensaries in Kisesa ward started to provide STI services using the syndromic approach in 1994 (one dispensary in the trading centre) and in 1996 (two rural dispensaries). These clinics saw 393 STI patients in 1996 and
380 in 1997; 59\% were women. The leading diagnoses for 1994-97 were genital discharge syndrome $(36.4 \%$ of all 1141 diagnoses), genital ulcer syndrome $(24.7 \%)$, and pelvic inflammatory disease $(21.8 \%)$. As there were approximately 8500 adults aged 15 to 44 living in Kisesa in 1996, the clinic data suggest an incidence less than $2 \%$ for genital discharge and genital ulcers. As such, there is a considerable discrepancy between the incidence of STIs based on self reports and on clinic data; this may reflect the non-utilisation of modern health services, the use of services outside the study area, or poor quality of self reported data.

There are no reasons to assume that the pattern of STIs in Kisesa is very different from other settlements in Mwanza Region. Studies in similar populations have shown that Herpes simplex virus (HSV-2) is common, with $20 \%$ of men and $50 \%$ of women aged 15 to 29 having antibodies ${ }^{39}$ ), although HSV-2 was responsible for less than $10 \%$ of genital ulcers in clinical studies. ${ }^{23}$ Similarly high rates of serosyphilis have also been observed, while gonorrhoea and chlamydia infection (mostly asymptomatic) was found in $2-3 \%$ of the adult male popula$\left.\operatorname{tion}^{40}\right)$. In a population based survey of men, $2.2 \%$ had gonorrhoea and $0.7 \%$ chlamydia infection, often asymptomatic. ${ }^{41}$ In antenatal clinics Trichomonas vaginalis infection was most common (27\% of 964 women), followed by active syphilis $(10 \%)$, Chlamydia trachomatis $(6.6 \%)$, and gonorrhoea $(2.1 \%) .{ }^{42}$

\section{DISCUSSION}

In this analysis we have focused on population characteristics of a poor semiurban and rural population in northwest Tanzania, and how these may directly and indirectly affect the epidemiology of HIV and other STIs. The overwhelming majority of the households are poor, which may be an important factor contributing to the high levels of short term mobility and migration within and outside the study area. High rates of annual migration and high proportions of household members not spending the night in the household were observed in all age groups, and especially among women under 25. Male villagers, however, appear to be involved in the bulk of short distance trading, mainly on bicycles, and from rural villages to trading centre and from trading centre to town.

It also appears that socioeconomic and sociocultural changes are affecting marriage systems. Marital instability was high. One in 10 women was divorced or separated at the time of the survey, large proportions of men and women had a divorce in their marital history, and divorce was a common reason for changing residence. The traditional system of marriage support may have weakened, as evidenced by the large proportion of less formal marriages and incomplete wealth transfer in association with marriage. More research on marriage patterns and how they affect mobility and vulnerability to infection in young women is urgently needed.

Sexual behaviour data indicate that premarital sex and multiple partnerships are common, while condom use was low. Most boys and girls were sexually active by the age of 16 or 17. The sexual partners of teenage girls were on average five (non-marital) to seven (marital partner) years older, and a significant proportion of teenage girls had a sexual partner aged over 30.

There are recurrent periods of different levels of risk related to marriage, and short and long term mobility is high. Extensive sexual mixing occurs by place and age and across social boundaries. The high levels of migration, marital instability, adolescent sexual activity, extensive sexual mixing, and sexually transmitted infections in the Kisesa population are all factors that could lead to high levels of HIV incidence. Yet, HIV prevalence and incidence data for 1994-97 suggest that, even though the epidemic has not reached its peak, prevalence levels of over $10 \%$ in the whole Kisesa ward adult population are not likely, as the overall incidence was below $1 / 1000$ person-years. HIV prevalence among young women (and 
young men) was relatively low compared with several other rural and urban areas studyed in eastern and southern Africa, ${ }^{43-47}$ and mortality among HIV infected persons was close to incidence. ${ }^{19}$ On the other hand, our study provides little evidence that adolescent sexual behaviour in Kisesa differs from other places with much higher incidence under the age of 20, either in terms of onset of sexual intercourse or in terms of mixing with older age groups. However, data are limited.

The spatial analysis of sexual mixing patterns of nonmarital partnerships showed that there is a limited level of mixing between the rural population and the trading centre (and beyond). Nearly eight of 10 partnerships in the trading centre and the rural villages are within the same location. Less than $10 \%$ of the partnerships are between the rural villages and trading centre. It is difficult to assess whether this level of spatial mixing is sufficient to enhance the spread of HIV from the trading centre to the rural areas and level the difference. In part, it depends on further mixing of partners within the rural villages. If those who have partnerships with the higher HIV prevalence trading centre (or the regional capital) have multiple partnerships within the study area, rapid spread of HIV is possible. There was only limited evidence that this may be the case. The difference in HIV incidence between the trading centre and rural villages suggests that HIV prevalence differences may become somewhat smaller than was the case in 1996-97, but a significant difference is likely to remain.

The size of the epidemic and consequent human suffering are unprecedented in recent African history, and one's first impression is that a full blown multi-intervention strategy aimed at all population groups in the society seems justified, with relatively more emphasis on the most cost-effective interventions. However, the reality is that in most countries with generalised epidemics it is only possible to follow a much more modest agenda than is desirable. The phase specific intervention strategy based on a dynamic typology of STI epidemics ${ }^{15}$ provides an epidemiological rationale for focusing interventions according to the phase of the epidemic. The epidemic in Kisesa is in a hyperendemic stage, in which it is most effective to focus interventions on spread networks and single out those with the riskiest behaviour, while maintaining general population interventions. The lack of resources in countries like Tanzania, however, prohibits a full scale intervention and in such situations focusing on spread networks should be a priority. Our analysis has shown that the spread networks are very extensive and fairly diffuse, with members often moving in and out of the network. Whether or not men and women are members of the spread network is influenced by their sociodemographic status, with marital status and mobility playing major roles. Poverty and lack of employment may be important underlying economic reasons. Such extensive networks may have a reproductive rate of infection just above unity and thus contribute to the spread of infection at a fairly slow rate, as opposed to more traditional core groups, such as sex workers, with higher reproductive rates of infection.

In a study in the industrialised world it was shown that focusing interventions on geographic "core" areas rather than on core groups was an effective way of reaching spread networks. ${ }^{48}$ In the context of Kisesa, which is likely to be similar in much of rural and semi-urban sub-Saharan Africa, this may also be the most effective and the most feasible approach. Such an approach should focus on places where new partner acquisition rates are high, following a methodology to identify high transmission areas developed by Weir et al. ${ }^{18}$ The "place focus" rather than "people focus" also reduces the risk of stigmatising core groups through the interventions. In Kisesa, focusing initially on the trading centre, with higher mobility, more bars, and higher HIV prevalence and incidence than in the nearby rural villages would appear to be the most cost-effective strategy. ${ }^{68}$ If resources suffice, additional work can be undertaken in the rural villages, although it is not clear whether the rural epidemic could be self sustaining if the interventions in Kisesa were in fact highly effective. The interventions should include social marketing of condoms, especially in the bars, traditional brew shops, and guest houses, and general AIDS education in places where people meet sexual partners, supported by improved STI services and adolescent sexual health programmes in schools. This high transmission area intervention strategy needs to be complemented with lower intensity basic general population interventions, including increased condom access, and would need to be continued as long as new partnership formation rates are high and until the risk of HIV and other STI are virtually eliminated.

\section{ACKNOWLEDGEMENT}

Sponsorship The TANESA project is financed by the Minister for Development Cooperation, the Netherlands. The analyses were supported by the USAID sponsored MEASURE evaluation project.

\section{Authors' affiliations}

J T Boerma, Department of Epidemiology, School of Public Health, and Carolina Population Center, University of North Carolina, USA

M Urassa, S Nnko, J Ng'weshemi, R Isingo, G Mwaluko,

Tanzania-Netherlands Project to Support AIDS control in Mwanza Region

B Zaba, London School of Hygiene and Tropical Medicine, Keppel St London WCl, UK

\section{REFERENCES}

1 Schwartlander B, Garnett G, Walker N, et al. AIDS in a new millennium. Science 2000;289:64-7.

2 Cohen B, Trussell J, eds. Preventing and mitigating AIDS in sub-Saharan Africa: research and data priorities for the social and behavioural sciences. Washington DC: National Academy of Sciences Press, 1996.

3 Caldwell JC, Caldwell P, Quiggin P. The social context of AIDS in sub-Saharan Africa. Popul Devel Rev 1989:15:185-234.

4 Carael M. Urban-rural differentials in HIV/STDs and sexual behaviour. In: Herdt G, ed. Sexual cultures and migration in the era of AIDS: anthropological and demographic perspectives. Oxford: Oxford University Press, 1997:107-26.

5 Wawer M, Serwadda D, Musgrave SD, et al. Dynamics of the spread of HIV-1 infection in a rural district of Uganda. BM 1991;303:1301-6.

6 Boerma JT, Urassa M, Senkoro K, et al. Spread of HIV infection in a rural area in Tanzania. AIDS 1999;13:1233-40.

7 Caldwell JC, Caldwell P. The neglect of an epidemiological explanation for the distribution of HIV/AIDS in sub-Saharan Africa: exploring the male circumcision hypothesis. Health Transition Review 1994;4(suppl):23-46.

8 Thomas JC, Tucker M. The development and use of the concept of a sexually transmitted disease core. J Infect Dis 1996;174(suppl 2):S134-43.

9 Morris M, Podhisita C, Wawer M, et al. Bridge populations in the spread of HIV/AIDS in Thailand. AIDS 1996;10:1265-71.

10 Gorbach PM, Sopheab H, Phalla T, et al. Sexual bridging by Cambodian men: potential importance for general population spread of STD/HIV epidemics. Sex Transm Dis 2000;27:320-6.

11 Laga M, Alary M, Nzila N, et al. Condom promotion, sexually transmitted diseases treatment, and declining incidence of HIV-1 infection in female Zairean sex workers. Lancet 1994;344:246-8.

12 Moses S, Plummer FA, Ngugi EN, et al. Controlling HIV in Africa: effectiveness and cost of an intervention in a high frequency STD transmitter core group. AIDS 1991;5:407-11.

13 Steen R, Vuylsteke B, DeCoito T, et al. Evidence of declining STD prevalence in a South African mining community following a core-group intervention. Sex Transm Dis 2000;27:1-8.

14 Cleland JC, Ferry B, eds. Sexual behaviour and AIDS in the developing world. London: Taylor and Francis, 1994.

15 Wasserheit JN, Aral SO. The dynamic typology of sexually transmitted disease epidemics: implications for STD prevention strategies. J Infect Dis 1996;174(suppl 2):S201-13.

16 Haour-Knipe M, Leshabari, Lwihula G. In: Gibney L, Di Clemente R, Vermund SH, eds. Preventing HIV in developing countries: biomedical and behavioral approaches. New York: Kluwer Academic/Plenum Publishers, 1999: 257-82

17 Ainsworth M, Teokul W. Breaking the silence: setting realistic priorities for AIDS control in less-developed countries. Lancet 2000 356:55-60.

18 Weir SS, Moroni C, Coetzee N, et al. A pilot study of a rapid assessment method to identify strategic areas for AIDS prevention in Cape Town, South Africa. Rome: Paper presented at a meeting on phase-specific strategies for the prevention, control and elimination of sexually transmitted diseases: implications for research, policies and programs, 3-6 October 2000 
19 Urassa $M$, Boerma JT, Isingo R, et al. The impact of HIV/AIDS on mortality and household mobility in rural Tanzania. AIDS 2001;15:2017-23

20 Nnko S, Boerma JT, Urassa M, et al. Sexual networking in Kisesa, Tanzania. Paper presented at an IUSSP conference on sexual networking, Chiang Mai, Thailand, February 2000.

21 Pool R, Washija R. Traditional healers, STDs and infertility in north-west Tanzania. In: Boerma JT, Mgalla Z, eds. Women and infertility in sub-Saharan Africa: a multi-disciplinary perspective. Amsterdam: Royal Tropical Institute Press, 2000.

22 World Bank. World development report 1996: from plan to market. Washington DC: World Bank, 1996.

23 Grosskurth H, Gray R, Hayes R, et al. Control of sexually transmitted diseases for HIV-1 prevention: understanding the impact of the Mwanza and Raki trials. Lancet 2000;355:1981-7.

24 Bongaarts J. A framework for analyzing the proximate determinants of fertility. Popul Dev Rev 1978;4:105-32.

25 Mosley WH, Chen LC. An analytical framework for the study of child survival in developing countries. In: Mosley WH, Chen LC, eds. Child survival: strategies for research. Popul Dev Rev 1984;10(suppl):25-45.

26 May RM, Anderson RM. Transmission dynamics of HIV infection. Nature 1987;326:137-142.

27 Bledsoe C, Pison G, eds. Nuptiality in sub-Saharan Africa: contemporary anthropological and demographic perspectives. Oxford: Clarendon Press, 1997.

28 Carael $M$. The impact of marriage change on the risks of exposure to sexually transmitted diseases in Africa. In: Bledsoe C, Pison G, eds. Nuptiality in sub-Saharan Africa: contemporary anthropological and demographic perspectives. Oxford: Clarendon Press, 1997:255-73.

29 Zaba B, Boerma JT, White R. Monitoring the AIDS epidemic using HIV prevalence data among young women attending antenatal clinics: prospects and problems. AIDS 2000;14:1633-45

30 Quinn TC. Population migration and the spread of types 1 and 2 HIV. Proc Natl Acad Sci USA 1994;91:2407-14.

31 Hunt CW. Migrant labour and sexually transmitted disease: AIDS in Africa. J Health Soc Behav 1989;30:353-73.

32 Lurie $M$, Harrison A, Wilkinson D, et al. Circular migration and sexual networking in rural KwaZulu/Natal: implications for the spread if HIV and other sexually transmitted diseases. Health Transition Review 1997;7(suppl 3):17-28.

33 Pison G, Le Guenno B, Lagarde E, et al. Seasonal migration: a risk factor for HIV infection in rural Senegal. J AIDS 1993;6:196-200.

34 Nunn AJ, Wagner HU, Kamali A, et al. Migration and HIV-1 seroprevalence in a rural Ugandan population. AIDS 1995;9:503-6.
35 Barongo LR, Borgdorff MW, Mosha F, et al. The epidemiology of HIV-1 infection in urban areas, roadside settlements and rural villages in Mwanza Regon, Tanzania. AIDS 1992;6:1521-8.

36 Nnko S, Washija R, Urassa $M$, et al. The dynamics of male circumcision practices in northwest Tanzania. Sex Transm Dis 2001;28:214-18.

37 Mgalla Z, Pool R. Sexual relationships, condom use and risk perception among female bar workers in north-west Tanzania. AIDS Care 1997;9:407-16.

38 Bloom SS, Isingo R, Urassa M, et al. It depends on where you live: community effects on the risk of HIV in rural Tanzania. Abstract TuPeC3443. Durban: World AIDS Conference, July 2000.

39 Obasi A, Mosha F, Quigley M, et al. Antibody to herpes simplex virus type 2 as a marker of sexual risk behaviour in rural Tanzania. J Infect Dis 1999; 179:16-24.

40 Grosskurth H, Mosha F, Todd J, et al. Impact of improved treatment of sexually transmitted diseases on HIV infection in rural Tanzania: randomised controlled trial. Lancet 1995;346:530-6.

41 Grosskurth H, Mayaud P, Mosha F, et al. Asymptomatic gonorrhoea and chlamydial infection in rural Tanzanian men. BM 1996:312:277-80.

42 Mayaud P, Grosskurth H, Changalucha J, et al. Risk assessment and other screening options for gonorrhoea and chlamydial infections in women attending rural Tanzanian antenatal clinics. Bull WHO 1995:73:621-30.

43 Shao J, Brubaker G, Levin A, et al. Population-based study of HIV-1 infection in 4086 subjects in Northwest Tanzania. J Acquir Immun Defic Syndr 1994;7:397-402.

44 Mulder D, Nunn A, Kamali A, et al. Decreasing HIV-1 prevalence in young adults in a rural Ugandan cohort. BM 1995;311:833-6.

45 Fylkesnes K, Ndlhlovu Z, Kasumba K, et al. Studying the dynamics of the HIV epidemic: population-based data compared with sentinel surveillance in Zambia. AIDS 1998;12:1227-34.

46 Fontanet AL, Messele T, Dejene A. Age- and sex-specific HIV-1 prevalence in the urban community setting of Addis Ababa, Ethiopia. AIDS 1998;12:315-22.

47 Mbizvo MT, Machekano R, McFarland W, et al. HIV seroincidence and correlates of seroconversion in a cohort of male factory workers in Harare, Zimbabwe. AIDS 1996;10:895-901.

48 Blanchard JF, Moses S, Greenaway C, et al. The evolving epidemiology of chlamydial and gonococcal infections in response to control programs in Winnipeg, Canada. Am J Public Health 1998;88: 1496-502. 